\title{
SENSITIVITY OF SERUM ENZYME INHIBITORS TO A VARIETY OF CANCER CHEMOTHERAPEUTIC AGENTS ${ }^{1,2}$
}

\author{
By FRANK W. ELLIS ANd PHILIP M. WEST \\ (From the Veterans Administration Hospital, Long Beach, Calif., and the School of Medicine, \\ University of California at Los Angeles, Calif.)
}

(Submitted for publication October 31, 1950; accepted, March 19, 1951)

In the palliative treatment of malignant disease, an objective method of determining the rapidity, degree, and duration of therapeutic response is a constant requirement. In a recent publication, Rhoads (1) has re-emphasized the importance of detecting delicate therapeutic effects in clinical cancer research. Standard methods such as serial $\mathrm{x}$-rays, blood counts, blood chemistry, observations of temperature, tumor size, changes in body weight, etc., are frequently of only limited usefulness for this purpose. Without a simple and objective measurement of tumor activity, valuable days or weeks may be needlessly spent on ineffective treatment. Similarly, reactivation of the disease may be difficult to detect by conventional methods, until it has produced irreversible damage and the patient can no longer tolerate intensive therapy.

Up to the present, there have been a few specific instances in which clinical laboratory tests have been helpful in following the effects of cancer treatment, e.g., serum acid phosphatase in carcinoma of the prostate, alkaline phosphatase in osteogenic sarcoma, and serum globulin levels in multiple myeloma, but these are obviously of limited application. Recently, however, it has been shown that the serum concentration of proteolytic enzyme inhibitors is influenced by various pathologic states, including malignant disease $(2,3)$. Although they possess no diagnostic value, two of these substances, chymotrypsin inhibitor and rennin inhibitor are nevertheless of remarkable clinical usefulness. In a study of cancer patients receiving nitrogen mustard therapy, West and

1 This work was supported in part by grants from the California Institute for Cancer Research through the Damon Runyon Cancer Fund.

2 Reviewed in the Veterans Administration and published with the approval of the Chief Medical Director. The statements and conclusions published by the authors are the result of their own study and do not necessarily reflect the opinion or policy of the Veterans Administration. associates (4) were able to relate the ratio of serum concentrations of these two factors to clinical signs of tumor activity. The present paper illustrates the sensitivity of the enzyme inhibitor response to a number of additional chemotherapeutic agents in several typical cases of neoplastic disease.

\section{METHODS}

Patients selected for case reports are from the Neoplastic Disease Service of the Veterans Administration Hospital, Long Beach, California. Although most have been subject to prolonged hospitalization and complete clinical and laboratory studies, only condensed case summaries dealing with pertinent factors are presented.

Quantitative determinations of the two inhibitors in the serum were made by methods previously described by West and Hilliard (2). Results were correlated with clinical and other laboratory evidence of changes in neoplastic activity. In all cases the existence of cancer had been proven by biopsy, and the patients were free of complications which have been shown to influence the enzyme inhibitor concentrations. Under these circumstances, as will be demonstrated, high rennin inhibitor and low chymotrypsin inhibitor levels are found to be associated with arrested growth or tumor regression while the reverse is correlated with actively progressing disease.

\section{EFFECTIVE CHEMOTHERAPY}

\section{Urethane in myelogenous leukemia}

Since the introduction of urethane for the treatment of myelogenous leukemia by Haddow and Sexton in 1946 (5), this drug has proved to be a valuable additional agent for palliative treatment of this disease. The case presented indicates the sensitivity of serum enzyme inhibitor concentrations to effective urethane therapy.

\section{Case No. 1 (Figure 1)}

A 28-year-old Mexican male was admitted to the hospital with complaints of fullness in the left upper quadrant for eight months, anorexia, weakness, fatigue, and 20 pounds weight loss of two months duration.

Abnormal physical findings included pallor, enlarged spleen extending beyond the mid-line and into the pelvis, 
liver enlargement three fingers' breadth below the costal margin, and a few small submaxillary, axillary, and inguinal lymph nodes.

Laboratory findings included entrance white blood cell count of 420,000 with $94 \%$ neutrophiles, (two myeloblasts, nine promyelocytes, 14 myelocytes, 20 stabs, 30 juveniles), $4 \%$ eosinophiles, $2 \%$ basophiles. The red blood cell count was 2,870,000 and hemoglobin $8.4 \mathrm{gms}$. Platelets 280,000 . Sternal marrow aspiration showed a typical picture of active chronic myelogenous leukemia with depression of erythroid activity.

The patient was started on oral urethane $6.0 \mathrm{gms}$. daily, which was subsequently gradually reduced to $2.0 \mathrm{gms}$. as shown in Figure 1. He improved steadily, the spleen reduced in size, hepatomegaly and lymphadenopathy disappeared, and he regained his feeling of well-being. He was discharged on maintenance doses of urethane.

Figure 1 illustrates a decrease both in white count and in chymotrypsin inhibitor activity coincident with the patient's improvement. During the charted period the hemoglobin increased from 8.4 to 13.2 gms., and the red blood cell count from $2,870,000$ to $4,510,000$ without transfusion of blood. Although urethane appears to have delayed action in chronic leukemia, it is of interest to note that its enzymatic effects are almost immediate and detectable many days ahead of the hematologic response. Assuming that urethane acts principally upon the immature marrow, de- layed depression of the peripheral white count is not unexpected. When the white blood count had decreased from over 400,000 to 30,000 , the drug was stopped, in spite of which the count continued to fall to a minimum of 10,25011 days later. However, upon discontinuing urethane, the enzyme inhibitors returned rapidly to pre-treatment levels. This occurred 10 days in advance of the corresponding rise in white blood cell count. Because the anti-leukemic action of urethane is reflected promptly in the enzyme inhibitor pattern, it has been found that maintenance doses of the drug may be selected more quickly on this basis.

Two additional cases of chronic myelogenous leukemia, and two of multiple myeloma have been treated with urethane with essentially similar clinical and enzymatic responses. In contrast to these, other types of leukemia, and several cases of carcinoma of the colon and prostate that received urethane without clinical improvement, failed also to show any change in the concentration of serum enzyme inhibitors.

\section{Cortisone in lymphosarcoma}

Rapid regression of lymphosarcoma following administration of cortisone was first observed by Heilman and Kendall (6) in tumor bearing mice.

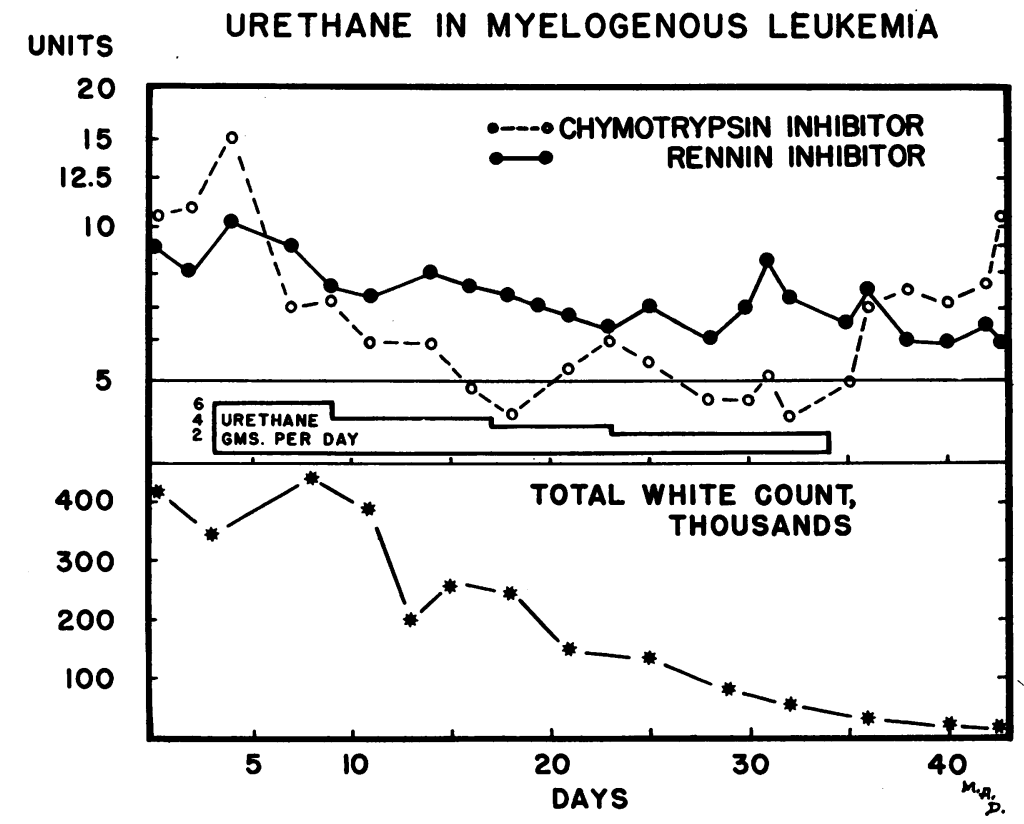

Fig. 1. Illustrating the Sensitivity of Chymotrypsin and Rennin Inhibitors to the Anti-Leukemic Action of Urethane 
More recently, Pearson and associates (7) have demonstrated that chronic lymphomas in man may respond similarly both to cortisone and $\mathrm{ACTH}$. Although results are admittedly of a temporary nature, nevertheless cortisone-induced regression of lymphosarcoma and the subsequent regrowth of the tumor provide an interesting test of the sensitivity of the two serum inhibitor substances to neoplastic activity.

\section{Case No. 2 (Figure 2)}

This 42-year-old white male had been followed by the tumor service since February 1949 when he was first hospitalized for bilateral groin swellings. Initial examination showed multiple inguinal, axillary, cervical, and occipital nodes. Biopsies of both inguinal area, and later of axillary nodes showed giant follicular lymphoblastoma, lymphosarcomatous type. Patient received $\mathrm{x}$-ray therapy in March-April 1949; nitrogen mustard in October 1949; second course of $\mathrm{x}$-ray in December-January 1950; third $x$-ray course March 1950 . He always responded well, maintained excellent physical condition, and was followed enzymatically at twice-monthly intervals, his satisfactory clinical course being mirrored in his favorable enzyme pattern.

When seen on May 22, 1950 he complained of anorexia, seven pound weight loss, low-grade fever, and enlargement of inguinal nodes. Chymotrypsin and rennin inhibitor levels at this time also suggested renewed activity and the patient was advised of the need for re-treatment.

On admission he complained of rather severe left flank and lumbar pain and showed multiple small cervical and occipital nodes, and discrete right inguinal nodes measuring 2 to $3 \mathrm{~cm}$. Laboratory work was within normal limits, as on multiple previous determinations: red blood cell count 4,510,000, hemoglobin 13.2 gms., white blood cell count 5,650 with $62 \%$ neutrophiles, $26 \%$ lymphocytes, $8 \%$ monocytes, $5 \%$ eosinophiles. No abnormal white blood cells were seen. $\mathrm{X}$-rays of the lumbar spine and abdomen showed no abnormalities.

The patient received cortisone, total of $1.0 \mathrm{gm}$. in seven days. Within 24 hours the back and flank pain had entirely disappeared, and the nodes were smaller. Within three days the cervical and occipital nodes had vanished, and the inguinal nodes were much reduced. He gained weight, felt entirely well, and returned to his job as truck driver.

Figure 2 illustrates a rapid decrease in serum chymotrypsin inhibitor immediately after cortisone $^{3}$ was started. This change was coincident with tumor regression and general clinical improvement. Also demonstrated is the transient effect of cortisone in this case, with relapse within three weeks. The patient was later treated with ACTH

\footnotetext{
3 Cortone acetate, Lot No. 415 , Merck and Co., Inc.
}

\section{CORTISONE IN LYMPHOSARCOMA}

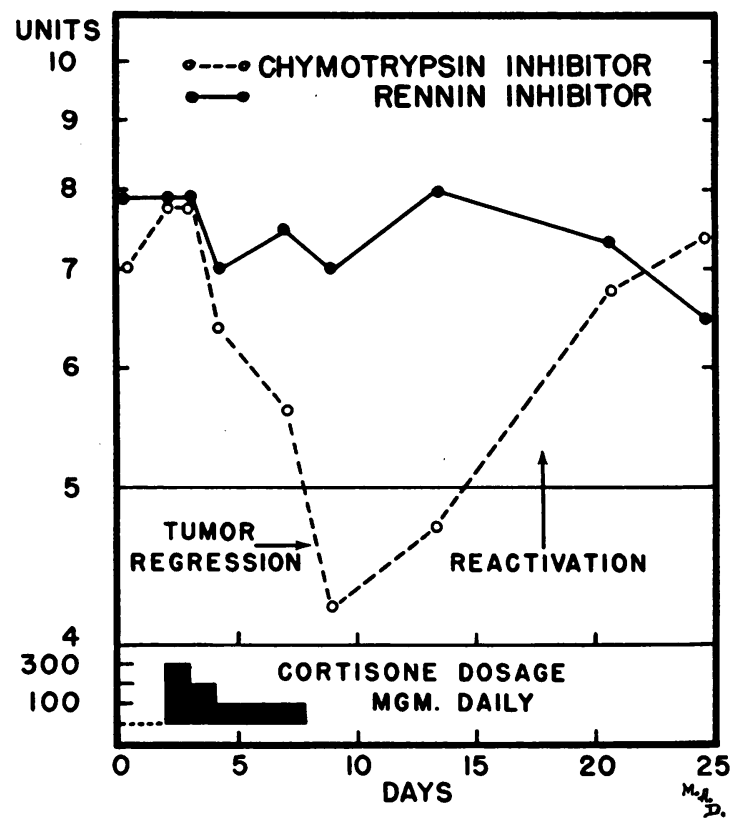

Fig. 2. Reduction of Serum Chymotrypsin Inhibitor CoIncident With CoRtisone-Induced Regression OF LYMPHOSARCOMA

for a similar period with excellent but equally temporary improvement both clinically and enzymatically. Because cortisone therapy did not result in an increased rennin inhibitor titer, it was predicted that the remission would be short, since in the course of this work it has been observed that prolonged remissions are usually associated with combined high rennin and low chymotrypsin inhibitor levels. For example, when nitrogen mustard was given to this same patient later, there was an increase in rennin inhibitor as well as a fall in chymotrypsin inhibitor, and more lasting clinical results were obtained.

\section{ACTH in acute leukemia}

The clinical investigations of Farber and colleagues (8) and Pearson and coworkers (9) indicate that incomplete and temporary remissions in acute leukemias of both children and adults can be induced with considerable regularity by the use of ACTH. With the dosage schedules that have been employed, however, the majority of adults have been refractory to subsequent therapy. In the case presented below, the parallelism between hematologic improvement and changes in the en- 
zyme inhibitors was studied by giving the drug intermittently in small amounts. Under these conditions repeated responses to $\mathrm{ACTH}^{4}$ were observed and the enzyme inhibitor pattern proved to be the most sensitive available index of disease activity.

\section{Case No. 3 (Figure 3)}

A 38-year-old white male was admitted to the hospital with complaints of pain in the left upper abdomen, profuse night sweats, weight loss, anorexia, all of one month's duration, and tarry stools and ankle edema, for two weeks.

Abnormal physical findings on entry included severe pallor, scattered petechiae on buccal mucosae, spleen enlarged to the level of the umbilicus, hepatomegaly of two fingers' breadth, and numerous bean-sized firm inguinal nodes.

Laboratory findings included white blood cell count of 18,900 with differential of $65 \%$ blast cells, unclassified, $12 \%$ neutrophiles, $25 \%$ lymphocytes. Red blood cell count 2,810,000, hemoglobin 8.1 gms. Platelets 210,000. Sternal marrow aspiration showed $95 \%$ blast cells, con-

${ }^{4}$ ACTH (Adrenocorticotropin), Lot No. 11302, Armour Laboratories. firming diagnosis of acute blastic leukemia. Subsequently cells of the myeloid series became prominent, particularly high percentages of myeloblasts and myelocytes. Total white blood cell count varied from 6,000 to 94,000 with percentage of blasts from $17 \%$ to $95 \%$.

The patient was treated with $\mathrm{ACTH}$, receiving four brief courses over a three month period. He deteriorated progressively, but with each period of ACTH administration showed an abrupt drop in percentage of myeloblasts, and improved sense of well-being, increased appetite, and disappearance of petechiae, which reappeared during intervals between ACTH effect. Prior to the second and third courses of ACTH the patient appeared moribund, with generalized bleeding, jaundice, high fever and prostration. Prompt improvement occurred with each course of ACTH.

The close parallelism between the enzyme inhibitor patterns and neoplastic activity, as indicated by numbers of circulating immature cells, is illustrated in Figure 3. As in Case 1, the enzyme inhibitor responses consistently preceded changes in the cell count of the peripheral blood, but in this more acute form of the disease the lag was only 24 to 48 hours. By using just sufficient $\mathrm{ACTH}$ to bring

\section{ACTH IN ACUTE LEUKEMIA}

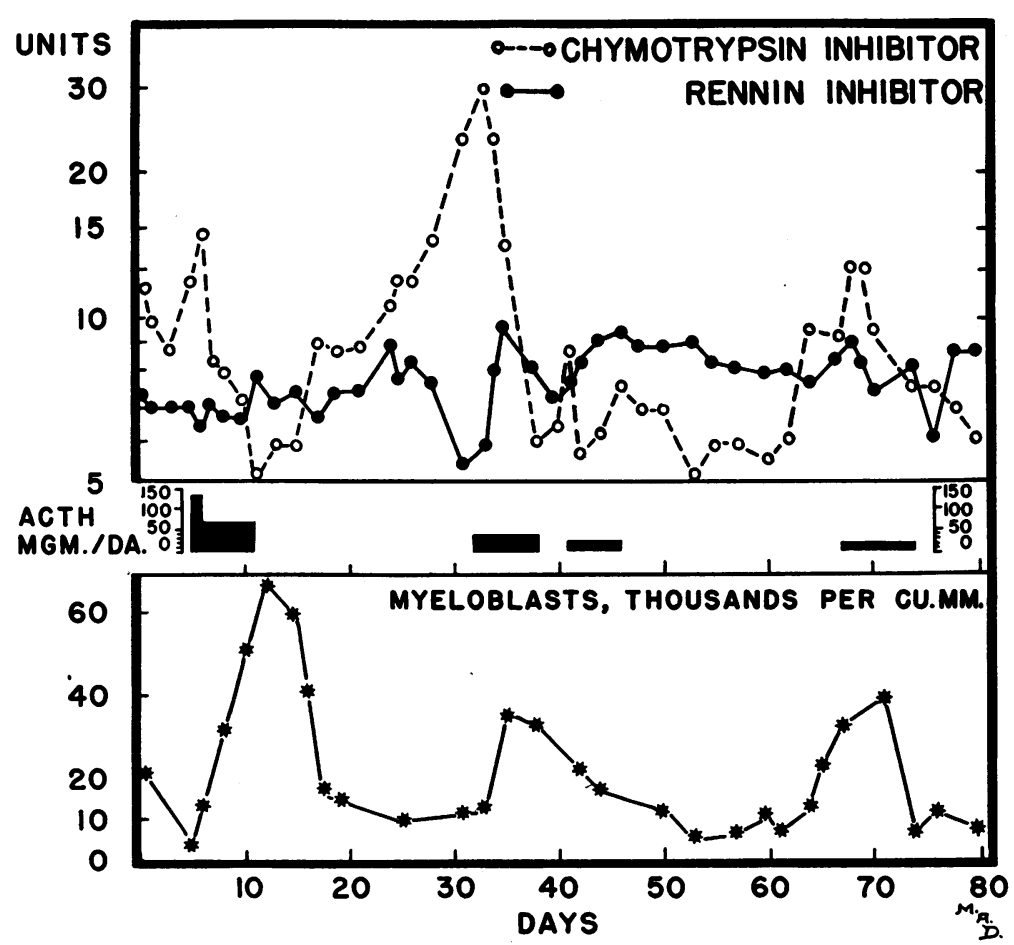

Fig. 3. Rapid Reversal of the Enzyme Inhibitor Pattern and Subsequent Hematologic Improvement with ACTH Therapy in Acute LEUKEMIA 


\section{TRIETHYLENE MELAMINE IN HODGKINS DISEASE}

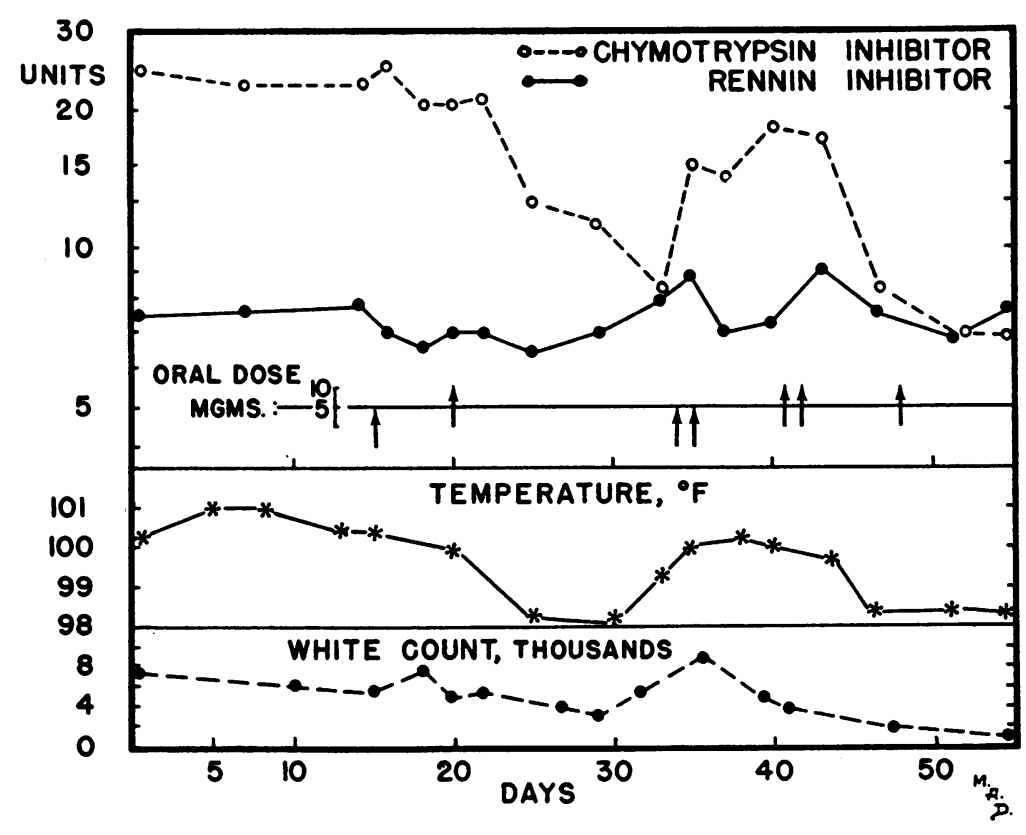

Fig. 4. Changes in Enzyme Inhibitor Balance Paralleling Cininical Response of Hodgkin's Disease to Triethylene Melamine Therapy

the enzyme pattern under relative control, repeated incomplete remissions were obtained in this patient.

Two other adults with acute leukemia, who were treated with ACTH for longer periods, also derived striking temporary clinical remissions accompanied by an abrupt fall in serum chymotrypsin inhibitor and rise in rennin inhibitor. However, second courses of ACTH were clinically and enzymatically ineffective in these cases.

\section{Triethylene melamine in Hodgkin's disease}

On the assumption that the anti-mitotic action of the nitrogen mustards depends on the highly reactive ethylene portion of the molecule, a number of synthetic substances have been prepared containing several ethylene groups. One of these compounds, 2,4,6-tris (1-aziridyl)-s-triazine, was shown by Sugiura and Stock (10) to exert an inhibitory effect on certain animal tumors. This drug has been made available for clinical investigation under the name triethylene melamine. ${ }^{5}$ It appears to

s Triethylene melamine kindly furnished by Dr. D. A. Karnofsky, Lederle Laboratories Division, American Cyanamid Co. possess definite value in palliative treatment of the lymphomas and, as indicated by the example below, its tumor inhibiting action traced by enzyme pattern is generally more rapid but less sustained than that previously reported for nitrogen mustard (4).

\section{Case No. 4 (Figure 4)}

The first manifestation of Hodgkin's disease in this 59-year-old white male was limited to right cervical adenopathy which had been treated by surgical resection and $x$-ray. Three years later the patient re-entered the hospital complaining of severe constipation, anorexia, nausea with occasional vomiting, and weight loss of 15 pounds. In the few weeks preceding entry he had had fever daily to $101^{\circ}$ with asthenia and malaise.

Physical examination showed a well-preserved 59-yearold white male, not obviously ill. Examination of the cervical area showed several old healed scars over the right sternocleidomastoid, in a region of thickening, induration, and pigmentation of the skin. There was no other adenopathy, and the spleen was not palpably enlarged. $\mathrm{X}$-rays of the chest and gastrointestinal tract were normal. The white blood cell count was 7,300 with $84 \%$ neutrophiles, $12 \%$ lymphocytes, $3 \%$ monocytes, $1 \%$ eosinophiles. Red blood cell count $3,540,000$, hemoglobin $10.8 \mathrm{gms}$.

The patient was treated with triethylene melamine as indicated in Figure 4. Response was rapid, with disap- 
pearance of fever and all gastrointestinal symptoms, reappearance of normal bowel movements, and disappearance of the right cervical nodes. A return of fever, nausea, and constipation within 10 days required repeated dosage of melamine. The second response was equally satisfactory, but severe leukopenia and anemia forced discontinuation of melamine in spite of the patient's statement that he felt "better than he had for six months," and was a "well man." He was subsequently treated with nitrogen mustard with prolonged clinical and enzymatic remission.

As illustrated in Figure 4, treatment with $10 \mathrm{mg}$. oral doses of triethylene melamine resulted in prompt reduction in serum chymotrypsin inhibitor levels, although $5 \mathrm{mg}$. doses were relatively ineffective in this respect. Rennin inhibitor was not appreciably increased so that rather intensive therapy was required to restore the normal balance between the two factors. The periods of maximum enzyme response were associated with disappearance of fever and development of leukopenia. In this case the enzyme determinations were actually the only objective means of planning an adequate treatment schedule, although the patient's feelings of well-being were parallel to the periods of depression in the chymotrypsin inhibitor levels.

It is of interest that two months preceding the charted period, samples of this patient's serum had demonstrated an enzyme pattern compatible with neoplastic activity, but treatment was postponed because of lack of other objective evidences of disease. Subsequent events proved this to be another instance of the unique usefulness of serum enzyme inhibitor determinations for detection of tumor reactivation when other clinical confirmation is difficult to obtain.

Similar results were obtained with melamine therapy in another case of Hodgkin's disease, reticulum cell sarcoma, and chronic myelogenous leukemia. Although both clinical and enzymatic responses were observed, they were of short duration and severe marrow depression prevented frequent repetition of effective doses.

\section{INEFFECTIVE CHEMOTHERAPY}

\section{Cortisone in osteogenic sarcoma}

In view of the reported inhibitory action of cortisone on mouse osteogenic sarcoma (11) and mouse rhabdomyosarcoma (12) this steroid was given for a trial period to a patient with rapidly growing metastatic osteogenic sarcoma. In addition, since enzymatic responses to cortisone in lymphosarcoma are usually definite and rapid it was considered important to make comparable observations in another sarcoma which is generally resistant to treatment.

\section{Case No. 5 (Figure 5)}

A 35-year-old white male was found to have osteogenic sarcoma of the right humerus and was treated with radical scapulo-thoracic amputation in February 1948. He remained clinically well until August 1949 when he developed a metastasis to the left seventh rib. This local metastasis was surgically removed for relief of pain. The patient then developed a slowly enlarging tumor mass at the site of surgery, and in May 1950 had rapid development of extensive pulmonary and abdominal metastases. This sudden increase in disease activity was associated with a soaring rise in chymotrypsin inhibitor levels and diminishing rennin inhibitor titers.

On this admission, the patient was ambulatory, showed recent weight loss, the previously mentioned surgical deformities, a hard fusiform mass $15 \times 5 \times 5 \mathrm{~cm}$. along the lateral aspect of the left seventh rib, and multiple stonyhard, grapefruit-sized masses in the abdomen, with considerable ascites. X-rays showed multiple calcified pulmonary metastases, and diffuse calcification throughout the abdomen, corresponding to the tumor masses.

Repeated laboratory work was not contributory to the present discussion, multiple blood counts, serum calcium,

\section{CORTISONE IN OSTEOGENIC SARCOMA}

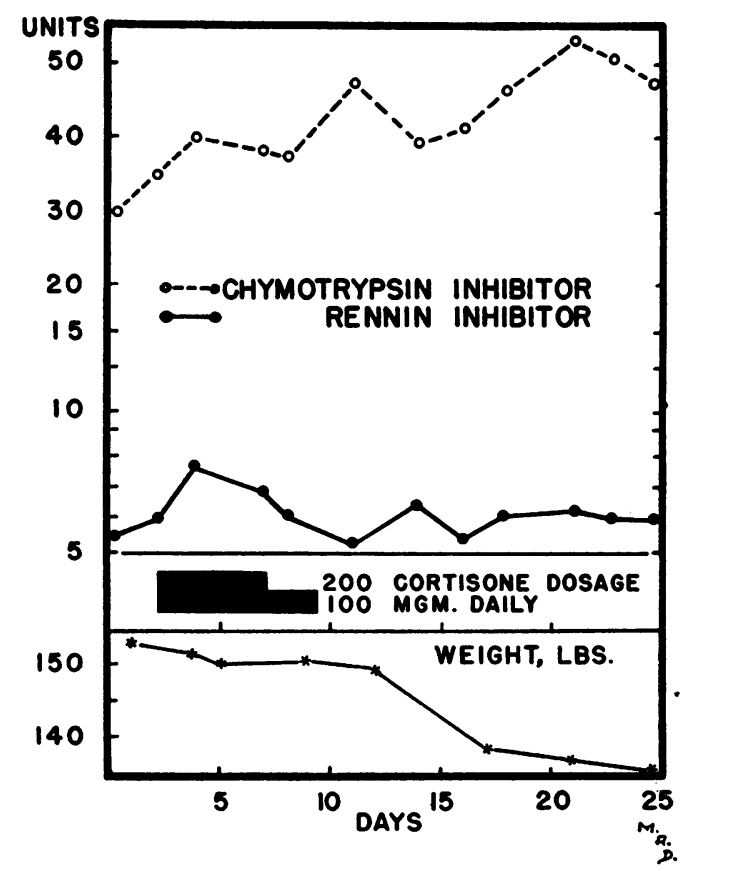

Fig. 5. Absence of Enzyme Inhibitor Changes in Osteogenic Sarcoma Resistant to Cortisone 
phosphorous, alkaline and acid phosphatases, and liver function tests being essentially within the normal ranges.

He received cortisone $1,200 \mathrm{mg}$. in eight days, with no observable clinical or enzymatic response. During the period of treatment the patient declined progressively and the tumor masses enlarged visibly.

This case illustrates the value of the two serum enzyme inhibitor determinations in confirming complete lack of response when a drug is used in a frankly investigational manner. The sensitivity of these proteolytic enzyme inhibitors to effective chemotherapy is such that an eight day trial period has been found ample for the evaluation of most drugs. Had there been even slight enzymatic evidence of decreased tumor activity during this period, further treatment with the hormone might have been considered in an attempt to achieve clinically detectable improvement.

\section{Progesterone in carcinoma of the prostate}

After a period of palliation by either orchiectomy, estrogen therapy or a combination of the two, most patients with carcinoma of the prostate finally become resistant to this type of treatment. It is of interest in such cases, therefore, to attempt to restrain the disease further by again altering the hormone balance. Clinical responses to progesterone and testosterone have been variable and individualized, and the sensitivity of these serum inhibitor substances has been of considerable assistance in our hands, in measuring the effects objectively and avoiding continued treatment with tumor stimulating or ineffective hormones.

\section{Case No. 6 (Figure 6)}

This 64-year-old white male with carcinoma of the prostate had had treatment for two and one-half years, consisting successively of radical prostatectomy, orchiectomy, estrogen administration and palliative deep $x$-ray therapy to multiple areas of osteoblastic metastases of the pelvis, femora, vertebrae, and ribs. For six months preceding the current admission he developed progressively severe pain in the involved areas of bony metastases, requiring large doses of narcotics for relief.

Physical examination showed only pallor, evidence of weight loss, and surgically absent prostate and testicles, although the patient was still well-nourished and ambulatory on crutches. X-rays confirmed the extensive bony metastases. Serum acid phosphatase was 7.8 Bodansky units (normal 2 to 9 units). The patient had a moderate hypochromic anemia corrected by whole blood transfusions.

Because he had previously responded well to changes

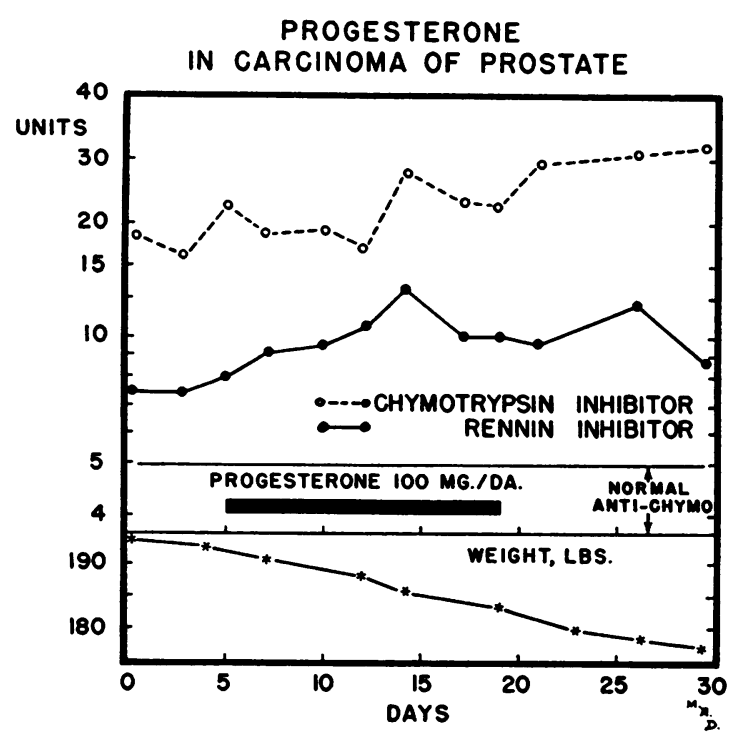

Fig. 6. Ineffective Treatment of Prostatic Carcinoma with Progesterone and CoRresponding Lack of Significant ENzyMe Inhibitor Response

in hormone balance to which he was now refractory, it was thought worth while to try another of the steroid hormones. Accordingly, with the unfavorable enzymatic pattern shown in the graph, he was given progesterone $100 \mathrm{mg}$. intramuscularly daily for 19 days. He received no benefit, his pain was unaffected, and he continued to lose weight.

In this case, previous serial enzyme inhibitor determinations following estrogen and testosterone administration and withdrawal had given excellent correlation with clinical status, and showed great sensitivity in response to these hormones. Therefore, since progesterone did not alter the enzyme balance, it was concluded that the drug was ineffective in this patient. Without such data, treatment might have been continued needlessly for a longer period, since clinical response in advanced metastatic prostatic carcinoma is frequently delayed, and early $\mathrm{x}$-ray changes are not expected. Serial acid phosphatase determinations were not helpful in this patient since previously they had remained within normal limits in spite of clinical exacerbations and remissions.

\section{Testosterone in carcinoma of the prostate}

\section{Case No. 7 (Figure 7)}

This 63-year-old white male was admitted to the hospital with complaints of increasing pain in the pelvis, low back, and posterior thighs for the preceding several weeks. 


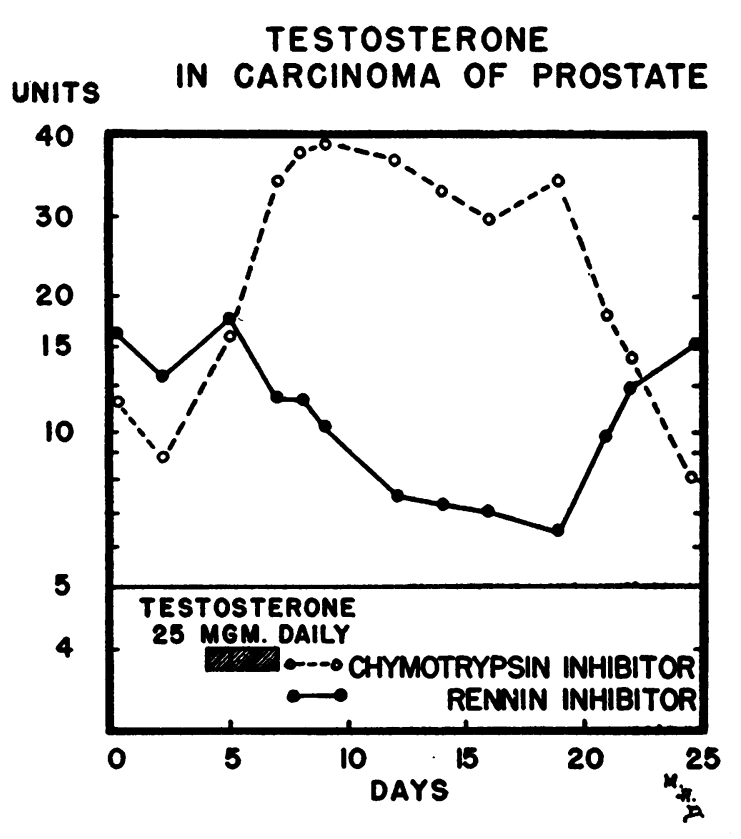

Fig. 7. Stimulation of Prostatic Carcinoma BY Testosterone Accompanied by Immediate Enzymatic Evidence of InCREASEd Tumor ACtivity

He had previously been followed in the out-patient department of the tumor service for 11 months following original diagnosis of adenocarcinoma of the prostate established by transurethral resection, following which bilateral orchiectomy was performed. The patient then felt quite well for five months, at which time he was started on ethinyl estradiol because of back, pelvic and thigh pain, due to extensive bony metastases. This relieved him for another five months, but he again developed increasingly severe pain which occasioned this present admission.

Physical examination on entry showed a well-developed, slightly obese 63-year-old white male complaining of moderately severe pelvic and back pain, and able to walk only a few steps with great difficulty. The testicles were surgically absent, and prostatic examination revealed scattered small stony-hard nodules in both lateral lobes. $\mathrm{X}$-rays showed extensive osteoblastic metastatic nodules involving the lumbar spine, sacrum, bony pelvis, and upper ends of both femora.

Soon after admission estrogen medication was discontinued, and the patient improved slightly, both clinically as manifested by a decrease in pain, and as measured by the enzyme inhibitor determinations. However, after a month of this observation, he again began to have increased pain in the areas of bony metastases. It was then decided to try testosterone because of previously experienced paradoxical palliative effects of male steroid administration in cases of prostatic carcinoma resistant to estrogens. Accordingly, the patient received testosterone propionate, 25 mg. intramuscularly daily for three doses. Within 24 hours of the first injection, his pain was acutely intensified, and he was hardly able to move about in bed. Coinci- dentally there was an immediate effect on the enzyme pattern, with marked elevation of the chymotrypsin and fall in the rennin inhibitor levels. Although five doses of 25 mg. each had been tentatively planned, the testosterone was stopped after the third dose because of the alarming change in the enzyme inhibitor pattern. On the fourth day, the patient was mentally confused, appeared prostrate, flushed, apprehensive, and required generous use of narcotics for pain relief. He gradually improved, and three weeks after stopping the testosterone was almost free of pain, fully ambulatory, and was discharged from the hospital. At the time of his discharge, his enzyme pattern showed declining chymotrypsin, and rising rennin inhibitor levels.

This case illustrates several interesting points. Figure 7 shows clearly the acute disturbance of enzyme inhibitor pattern immediately after testosterone administration. Also shown is the return of these inhibitors to pre-treatment levels following cessation of the androgen. The clinical parallelism with these determinations was disconcertingly convincing. Of further interest is the fact that the patient improved enough to be discharged from the hospital following recovery from this period of acute androgen-induced exacerbation. Although several other estrogenresistant cases of prostatic carcinoma with previous orchiectomy have shown a similar sensitivity to small doses of testosterone, the same response has not been obtained in all such patients. In no other malignancies, except carcinoma of the breast and prostate, has any change in chymotrypsin and rennin inhibitor concentrations been observed following the administration of androgens.

\section{Guanazolo in acute leukemia}

Considerable interest has been created by the work of Kidder and associates $(13,14)$ in the possibility of selectively blocking nucleoprotein synthesis in neoplastic tissues by the administration of unnatural purines. Guanazolo ${ }^{\circ}$ (8azaguanine), a synthetic guanine antagonist, successfully inhibited the progress of some carcinomas and leukemias in mice. Unfortunately, similar results have not been reported in human malignant disease. An example of the clinical trial of guanazolo therapy is presented in which even minor changes in serum enzyme inhibitor

' Guanazolo, Lot No. 7-9710, kindly furnished by Dr. D. A. Karnofsky, Lederle Laboratories Division, American Cyanamid Co. 
balance failed to appear and the course of the disease was unaltered.

\section{Case No. 8 (Figure 8)}

A 40-year-old white male was transferred to this hospital with the previously established diagnosis of acute leukemia. Complaints of about six weeks duration included marked weakness, fatigue, fever, and purpura of forearms, calves, and thighs.

Physical examination on admission showed a tired-looking, weak, sallow-complexioned white male appearing acutely and chronically ill. Abnormal findings included swelling of the soft tissues bilaterally in the submaxillary area, hyperplasia and friability of the gums with areas of ulceration, several small areas of absorbing blood pigment over the calves and forearms. There was no peripheral adenopathy nor palpably enlarged spleen. Laboratory findings on entry included white blood cell count of 90,000, with differential count of $95 \%$ neutrophiles (including one stab cell, three promyelocytes, and 83 blasts), a red blood cell count of 2,460,000, hemoglobin 9.6 gms. Platelets 110,000 .

The patient pursued a progressively downhill course of three months duration. He was treated with the usual supportive methods including multiple whole blood transfusions, and antibiotics as needed. He was tried successively on several drugs of the "metabolic blocking agent" classification, including guanazolo, of which he received

\section{GUANAZOLO IN ACUTE LEUKEMIA}

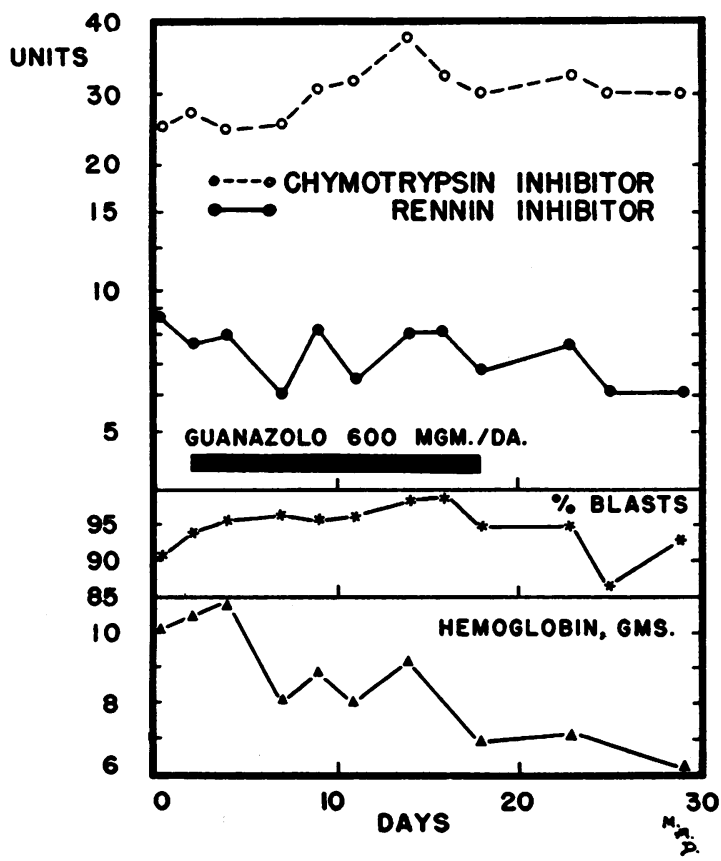

Fig. 8. Fatlure of Guanazolo to Induce Remission in Acute Leukemia or to Alter Enzyme In hibitor Concentrations
$600 \mathrm{mg}$. orally daily for 14 days. There was no noticeable clinical improvement during this period.

Figure 8 illustrates complete absence of serum enzymatic inhibitor response to guanazolo therapy. Clinically, the patient continued to deteriorate while the percentage of blasts in the peripheral blood remained between 85 and $90 \%$. The red blood cell count and hemoglobin declined steadily during this period, in spite of daily transfusions. In this instance, it is apparent that guanazolo, which was of therapeutic value in experimental leukemia, did not exert a similar effect in the comparable disease in man.

\section{DISCUSSION}

The sensitivity of chymotrypsin and rennin inhibitors of the serum to changes in neoplastic activity is of theoretical as well as practical interest. The mechanism by which rapid alteration in the balance between the two factors is brought about in response to effective chemotherapy is not known. As illustrated by the cases presented in this paper, there is no direct action of the medication on these enzyme systems. Only if the drug exerts a stimulating or restraining effect on the tumor itself will the enzyme inhibitor concentrations change. Serial determinations of these enzyme inhibitors appear therefore to yield information by which the course of the malignant process may be charted. The value of such data in the clinical investigation of palliative drugs and in management of the cancer patient has been substantiated by daily use of the method for three years, during which time over 30,000 determinations have been made.

Of necessity, in order to demonstrate the parallelism between the action of a drug on the tumor and changes in the enzyme inhibitor pattern, cases had to be selected in which the effects of treatment were clinically obvious. In by far the majority of cases encountered in a tumor service, however, the enzyme results constitute the only simple and objective indicator of the patient's progress. Frequently an individual with cancer, in his enthusiasm over a new drug, may feel that he is benefited but the enzyme patterns reveal whether or not there is any basis for his subjective improvement. On the other hand, highly significant but weak, sub-clinical effects on the 
tumor may be produced by an agent under investigation which would have escaped notice without a sensitive measure of neoplastic activity. Likewise, reactivation of tumor growth after a period of remission may often be detected enzymatically long before symptoms appear, thereby making it possible to give further palliative treatment earlier and more effectively.

In the interpretation of enzyme inhibitor determinations, it should be emphasized that the ratio between the two factors is as important as their individual absolute values. This point has been discussed in detail by West, Rapaport, and Tempereau (4) in describing the relationship between the enzyme inhibitors and clinical response to nitrogen mustard therapy. The aim of treatment is to produce and maintain the serum chymotrypsin inhibitor at five units or less, and rennin inhibitor at 15 units or more, since it has been found that this equilibrium between the two factors is uniformly associated with complete tumor inhibition or regression. Usually the higher the rennin inhibitor titer, the more complete and prolonged a remission is likely to be. Patients with known residual disease which has remained inactive for many years, show in addition to normal serum chymotrypsin inhibitor, the highest rennin inhibitor levels of all, at times reaching 100 units. Observations to date have suggested that as a working hypothesis the chymotrypsin inhibitor might be considered an index of "neoplastic activity" and the rennin inhibitor in some unexplained manner a reflection of "host resistance." Experiments are in progress to determine the source of these enzyme inhibitors, their biochemical nature, and the mechanism of their release into the circulation.

\section{SUMMARY}

1. Evidence is presented which indicates that the equilibrium between chymotrypsin and rennin inhibitors of the serum may be utilized as a sensitive measure of the effectiveness of palliative therapy in the neoplastic diseases.

2. Several examples of effective chemotherapy are described in which, regardless of the drug used or the type of the malignancy, inhibition of tumor growth is reflected by similar changes in the concentration of serum enzyme inhibitors.
3. Ineffective chemotherapy does not alter the enzyme inhibitor pattern while tumor stimulating agents produce enzymatic changes associated with increased neoplastic activity.

4. The sensitivity, consistency and close correlation of these two factors with the clinical status of the cancer patient suggest that the method possesses considerable practical, as well as research value in assisting the charting of the course of neoplastic disease.

\section{ACKNOWLEDGMENTS}

The authors are greatly indebted to Willard F. Keye and Bronnetta L. Scott for technical assistance, and to Mary A. Dubbin for preparation of the figures.

\section{REFERENCES}

1. Rhoads, C. P., Present trends in cancer research, a general discussion. Vet. Admin. Tech. Bull., 10-66, Aug. 9, 1950.

2. West, P. M., and Hilliard, J., Proteolytic enzyme inhibitors of human serum in health and disease. Proc. Soc. Exper. Biol. \& Med., 1949, 71, 169.

3. West, P. M., and Hilliard, J., Proteolytic enzyme inhibitors of the blood in relation to neoplastic diseases; preliminary report. Ann. West. Med. \& Surg., 1949, 3, 227.

4. West, P. M., Rapaport, S. I., and Tempereau, C. E., Enzymatic evaluation of therapeutic agents in cancer. Cancer, 1951, 4, 177.

5. Haddow, A., and Sexton, W. A., Influence of carbamic esters (urethanes) on experimental animal tumours. Nature, 1946, 157, 500.

6. Heilman, F. R., and Kendall, E. C., Influence of 11dehydro-17-hydroxycorticosterone (compound E) on growth of a malignant tumor in the mouse. Endocrinology, 1944, 34, 416.

7. Pearson, O. H., Eliel, L. P., and Rawson, R. W., Regression of lymphoid tumors in man induced by ACTH and cortisone, in Proceedings of the First Clinical ACTH Conference, J. R. Mote, Editor. The Blakiston Co., Philadelphia, 1950, p. 318.

8. Farber, S., Schwachman, H., Toch, R., Downing, V., Kennedy, B. H., and Hyde, J., The effect of ACTH in acute leukemia in childhood, in Proceedings of the First Clinical ACTH Conference, J. R. Mote, Editor. The Blakiston Co., Philadelphia, 1950, p. 328.

9. Pearson, O. H., Eliel, L. P., and Talbot, T. R., Jr., Remission in acute leukemia induced by ACTH. Cancer Research, 1950, 10, 235.

10. Sugiura, K., and Stock, C. C., Action of 3-Bis (Bchloroethyl) aminomethyl-4-methoxy-methyl-5- hydroxy-6-methyl pyridine di-hydrochloride, 2,4,6-tris (1-aziridyl)-s-triazine and 5-amino-7-hydroxy-1H- 
v-triazolo $(d)$ pyrimidine on carcinoma, sarcoma, osteogenic sarcoma, lymphosarcoma, and melanoma in animals. Cancer Research, 1950, 10, 244.

11. Sugiura, K., Stock, C. C., Dobriner, K., and Rhoads, C. P., The effect of cortisone and other steroids on experimental tumors. Cancer Research, 1950, 10, 244.

12. Higgins, G. M., Woods, K. A., and Bennett, W. A., The influence of cortisone (compound $E$ ) upon the growth of a transplanted rhabdomyosarcoma in $\mathrm{C}_{3} \mathrm{H}$ mice. Cancer Research, 1950, 10, 203.

13. Kidder, G. W., and Dewey, V. C., The biological activity of substituted purines. J. Biol. Chem., 1949, 179, 181.

14. Kidder, G. W., Dewey, V. C., Parks, R. E., Jr., and Woodside, G. L., Purine metabolism in tetrahymena and its relation to malignant cells in mice. Science, 1949, 109, 511. 